\title{
THE RAPID AND GREEN HAIR ANALYSIS METHOD DEVELOPMENT USING FTIR FOR PAPAVERINE HCL DETERMINATION
}

\author{
ILMA NUGRAHANI ${ }^{1}$, STEPHANIE SULISTIANA ${ }^{1}$, SLAMET IBRAHIM ${ }^{1}$
}

School of Pharmacy, Bandung Institute of Technology, Indonesia

Email: ilma_nugrahani@fa.itb.ac.id

Received: 07 Dec 2018, Revised and Accepted: 12 Feb 2019

\begin{abstract}
Objective: This study was aimed to develop a rapid analysis using FTIR (Fourier Transform Infra-Red) for papaverine hydrochloride (HCl) determination in the hair sample, supported by a mathematically manipulation; which never been reported before in toxicology and forensic analysis.

Methods: Firstly, the method was checked its validity to ensure the feasibility for the quantitative purpose. The absorbance spectrums were collected by measure the drug, matrix, and its mixture. A spectra which showed the best specificity and linearity then was selected and derived. Afterwards, the area under the curve (AUC) was measured. A series of concentration was used for compose the calibration curve. Based on the result, some validation parameters were checked thoroughly. Further, for sample preparation, hair was collected non-invasively, then was decontaminated using soap. Next, it was immersed into a papaverine $\mathrm{HCl}$ solution at a concentration of $25 \mathrm{mg} / \mathrm{ml}$ along days. Finally, the amount of drugs absorbed were measured by the developed method using FTIR.
\end{abstract}

Results: Experimental data showed that all validation parameters could be fulfilled by the developed method. The selected spectra for the content determination was $1320-1230 \mathrm{~cm}^{-1}$. Its linearity was represented by a correlation coefficient value (r) $\geq 0.9999$, variation coefficient (Vxo) $\leq 2.0 \%$. The limit of detection (LOD) was $0.00618 \% \mathrm{w} / \mathrm{w}$, meanwhile, the limit of quantitation (LOQ) was $0.02060 \% \mathrm{w} / \mathrm{w}$, respectively. The percent recovery was in the range $97-103 \%$ with the relative standard deviation (RSD) was $\leq 2.0 \%$. The drug has detected after $72 \mathrm{~h}$ immersion, moreover, after $192 \mathrm{~h}$ the concentration gained was $0.1594 \pm 0.0011 \% \mathrm{w} / \mathrm{w}$.

Conclusion: As the conclusion, FTIR absorbance-derivative method is adequate as a rapid procedure for determine papaverine HCl in the hair sample. This method shows the appropriate of specificity, accuracy and precise. In addition, it shows the advantages of simplicity, green/ecofriendlier, and cost-efficiency.

Keywords: Papaverine HCl, Hair analysis, Rapid method development, FTIR, Quantitative, Absorbance derivate, Mathematically manipulation, Direct measurement, Non-invasive, Toxicology, Forensic, Green analysis

(C) 2019 The Authors. Published by Innovare Academic Sciences Pvt Ltd. This is an open-access article under the CC BY license (http://creativecommons.org/licenses/by/4.0/) DOI: http://dx.doi.org/10.22159/ijap.2019v11i2.31225

\section{INTRODUCTION}

Time by time, not only drug production developed into more advanced but also followed by the growth of distribution facilities. The development of drug distribution facilities, the spread becomes wider and can be easily obtained by various layers of society. Thus, there is a high probability of misuse of the effects given by the drug. One class of drugs that are often misused is psychoactive drugs. The compounds work in the central nervous system that can change consciousness, mood and mind. These effects on the central nervous system are generally expected by users to get pleasure and avoid pain. The change in brain function can cause dependence. These compounds affect the processes of perception, emotion, and motivation in the brain [1, 2]. One drug that has widely been misused for a long time is papaverine $\mathrm{HCl}$, which belongs to the opium group.

With the increasing number of misuse of the use of papaverine $\mathrm{HCl}$, a simple but accurate test method is needed to detect misuse. In this experiment, hair analysis was aimed to confirm its suitability to test this drug. The advantages of using hair samples for testing include fast, simple and non-invasive to collect. Besides, the sampling can be monitored easily, so that it can reduce fraud by donors. In addition, this specimen is very stable compared to other sample forms and can be storage in the ambient condition. Moreover, hair can save the drug, which was consumed a few months beforehand. As a comparison, urine is generally only 2-3 d for most drugs, meanwhile blood and saliva approximately one day merely. Last but not least, it also can be used to identify the long-term abuse, and make it possible to analyze abuse from month to month in more detail [3-7].

The initial hypothesis of this study was that there is a distribution of papaverine $\mathrm{HCl}$ compounds from the blood into hair and stored there "forever" [8-10]. The aim of this study was to detect and quantify the psychoactive drug in hair samples using FTIR. Infrared analysis has been applied a long time to identification. In fact, some previous researches has proved that this method can be used for the quantitative purpose, in a simple and rapid way [11, 12]. Small compounds with high hydrophobicity and the presence of ionizable base groups tend to bind to hair structures $[13,14]$. As a psychotropic agent, papaverine $\mathrm{HCl}$ is a hydrophobic substance which need an organic solvent to dissolve it [15]. The active compound has a minimal effect on the central nervous system, although large doses can cause sedation and drowsiness in some patients. Side effects that can be caused, includes depressant and sedation in the central nervous system. These side effects can be misused by the users [16].

The IR absorption spectrum obtained can be described as a characteristic of a chemical compound, because it can read almost all of the difference's vibration energy levels $[17,18]$. Actually, some experiment of hair analysis has been reported using FTIR [19-21]. However, this method has the lack specificity due to many spectrum appearances. Even so, the mathematical manipulation by derivation of absorbance will be applied to improve its selectivity and sensitivity. Thereof, this method was expected can be utilized to detect and measure papaverine $\mathrm{HCl}$ in a rapid a green procedure, without any organic solvent used.

\section{MATERIALS AND METHODS}

\section{Material and apparatus}

The instrument and tool-using in this experiment were FTIR Jasco4200 type A (Japan), a milligram electronic scales (Mettler Toledo, USA), small marble mortar, pestle, pellet pressing, oven, beaker, measuring flask. Meanwhile, the materials were papaverine $\mathrm{HCl}$ standard (USP), ethanol 95\% (Merck, Germany), potassium bromide 
(Merck, Germany), human hair samples (woman, black color without dying).

\section{Methods}

Present research was conducted in several stages. First step was sample preparation, the second was the validation of FTIR method, then the last was an application of it to analyze the drug concentration in the hair sample.

\section{Development of the FTIR method}

Firstly, standard of the drug was analyzed using FTIR to get the transmittance spectrum. Then, it was transformed to absorbance, next was derivated mathematically using the program included in the instrument. The spectra which shown clear and was not overlapped is the choice. The selected spectra then were investigated its linearity, detection and quantification limit, range of analysis, afterwards evaluated accuracy and precision of intra-and inter-day. Further, the hair sample was prepared to be analyzed. Some head hairs were soaked with the drug solution along eight days. Sampling was conducted every day and measured.

\section{Measurement of papaverine $\mathrm{HCl}$ standard}

Papaverine $\mathrm{HCl}$ was dispersed with potassium bromide in a series of the concentration of $0.25-1.5 \% \mathrm{w} / \mathrm{w}$. A total of $10 \mathrm{mg}$ of the mixture was taken and pressed. Then it was measured using FTIR Jasco-4200 type A in waves of 4000 to $400 \mathrm{~cm}^{-1}$, three times. The spectrum was corrected against the baseline and converted into its derivatives so that it was clearer to increase the selectivity. The area under the curve was measured in several ranges of the wave numbers. Determination of the wave number range was done by plotting the concentration of papaverine $\mathrm{HCl}$ to the area under the curve (AUC) of the derivated absorbance-spectra. The range of the wave numbers which could produce a strong and consistent peak was observed and selected.

\section{Validation method}

Specificity test was performed by a measured spectrum of hair samples with and without papaverine $\mathrm{HCl}$. Then, all resulted were overlaid. An independent spectra which were the cleanest and no interference of the matrix, was selected.

The standard concentrations of papaverine $\mathrm{HCl}$ in potassium bromide was prepared $(0.25 ; 0.50 ; 0.75 ; 1.00 ; 1.25$ and $1.50 \% \mathrm{w} / \mathrm{w})$. For each concentration, three measurements were taken. The transmittance spectrum then was transformed to be absorption, next was derivated mathematically using the software included in the instrument. The area under the curve (AUC) was calculated, further was plotted against concentration. The curve yielded was observed its linearity. The acceptability criterion for linearity is the correlation coefficient $(r) \geq 0.999$ and the coefficient of variat ion from the regression function $\leq 2.0 \%[22,23]$.

The LOD and LOQ can be estimated from the standard curve produced by the following equation:

$$
\begin{gathered}
\mathrm{LOD}=3 \times \mathrm{Sb} / \mathrm{b} \\
\mathrm{LOQ}=(10 \times \mathrm{Sb}) / \mathrm{b}
\end{gathered}
$$

With $\mathrm{Sb}$ is the standard deviation, and $\mathrm{b}$ is the slope of the curve obtained [23, 24].

The concentration range used for the linearity test, accuracy and precision were determined from the observations and the resulting calibration equations.

Accuracy test then was carried out by measuring the standard of papaverine $\mathrm{HCl}$ with concentrations of 80,100 and $120 \%$, three times for each concentration. Acceptance criteria are recovery of $97-$ $103 \%[24,25]$.

Precision test was carried out by measuring the concentration $100 \%$ of papaverine $\mathrm{HCl}$, as much as six times a day, and measurements were taken in three different days. The acceptability criterion for precision is the relative standard deviation (RSD) $\leq 2 \%[22,24]$.

\section{Determinations of papaverine $\mathrm{HCl}$ level in the sample}

The hair-sample was prepared by collecting 20 strands of human hair with the length of $10 \mathrm{~cm}$. These were washed separately with 1 $\mathrm{ml}$ of liquid detergent to remove external contaminants and rinsed thoroughly with distilled water. Next, it be filled into and soaked in a papaverine $\mathrm{HCl}$ solution with a concentration of $250 \mathrm{mg} / 25 \mathrm{ml}$ along eight days. The samples then were air-dried. Sampling was carried out every $24 \mathrm{~h}$. In each measurement, one strand of hair was pulverized using a marble mortar. Further, the sample was added and dispersed by potassium bromide crystal then to be pressed to produce a pellet. Finally, it be analyzed using FTIR.

\section{RESULTS AND DISCUSSION}

\section{Measurement of papaverine $\mathrm{HCl}$ standard}

The development method was begun by quantifying the concentrations of papaverine $\mathrm{HCl}$ in potassium bromide. The spectrum would show the relationship between the papaverine $\mathrm{HCl}$ 's concentrations and percent transmittance. The greater of concentration will produce the smaller of the percentage of transmittance. It due to the more lighting is absorbed as shown in fig. 1. It is in accordance with the Lambert-Beer law which states the concentration is proportionally direct to absorbance and inversely to the logarithmic transmittance.

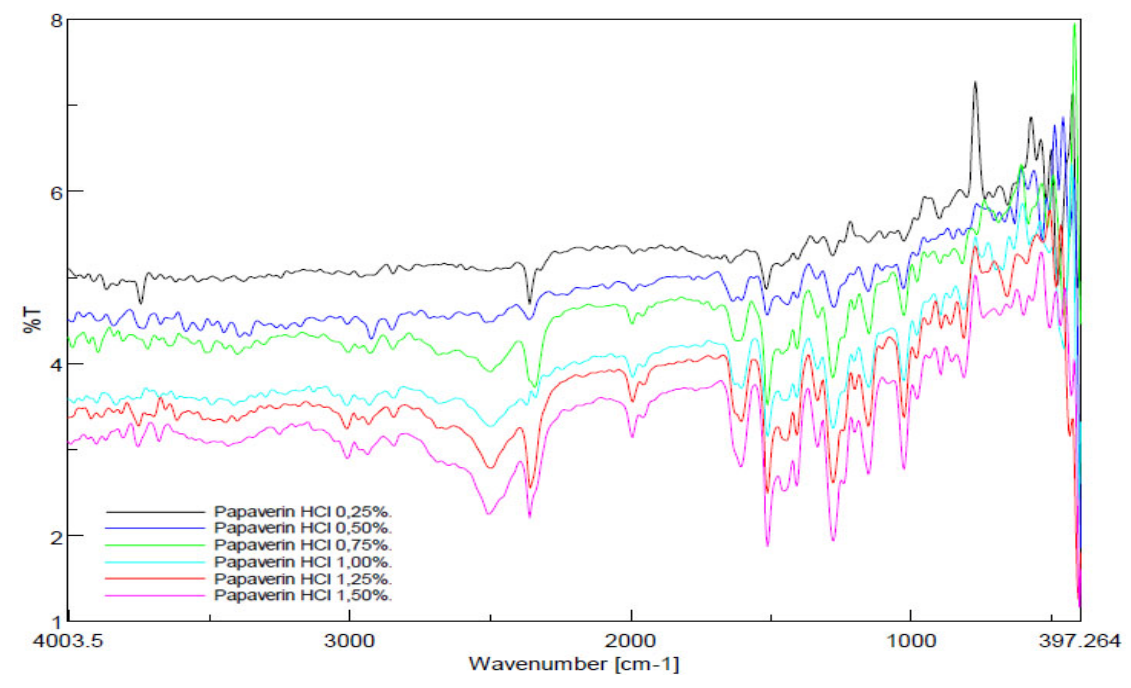

Fig. 1: The overlaid spectra of a series of papaverine HCl's concentration 


\section{Spectra derivatization}

The FTIR spectrum obtained was next transformed to absorbance and afterwards was derivatized. Before derivatization was carried out, the baseline correction was performed. From the spectrum of derivatization results obtained AUC. The AUC value at various wavenumbers that produces a strong and consistent peak is plotted against the concentration of papaverine $\mathrm{HCl}$ in potassium bromide $(\% \mathrm{w} / \mathrm{w})$ and then determines its linearity. Fig. 2 shows the spectrums of derivatization of the standard of papaverine $\mathrm{HCl}$.

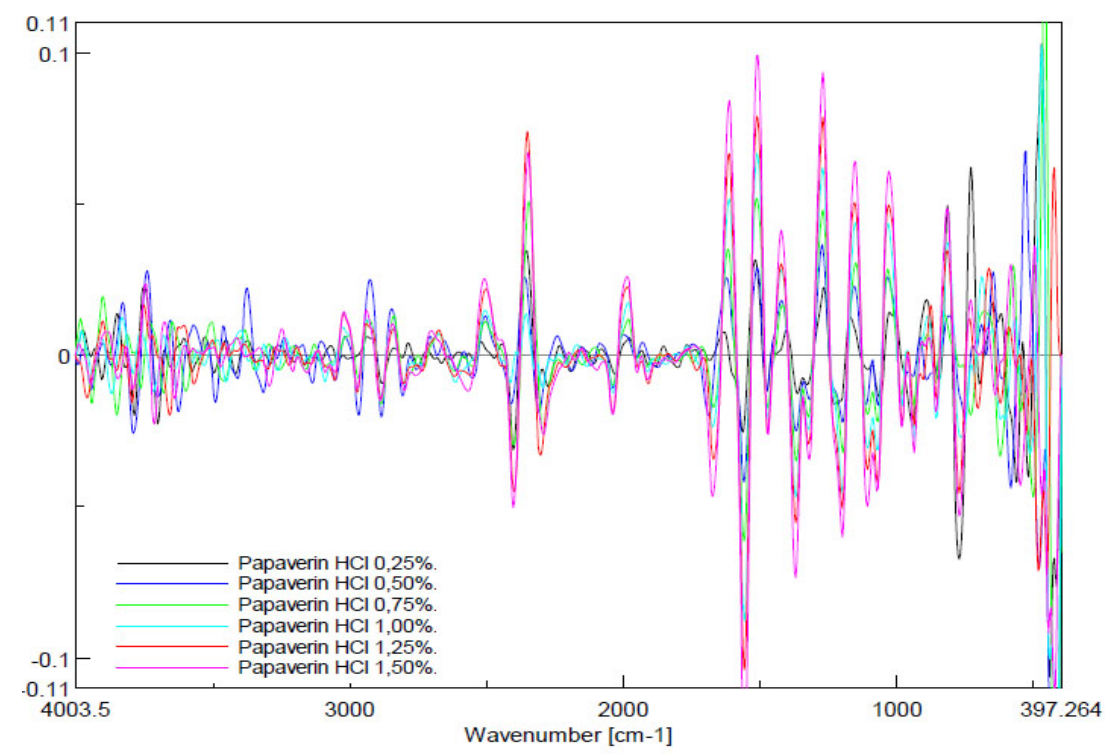

Fig. 2: Overlay of papaverine $\mathrm{HCl}$ absorbance spectra derivative in a varies concentration

Furthermore, the derivated spectrums are shown in fig. 3. Next, it was selected to be used to determine the range of wave numbers by choice one spectra that has the best linearity and was not interfered by matrix.

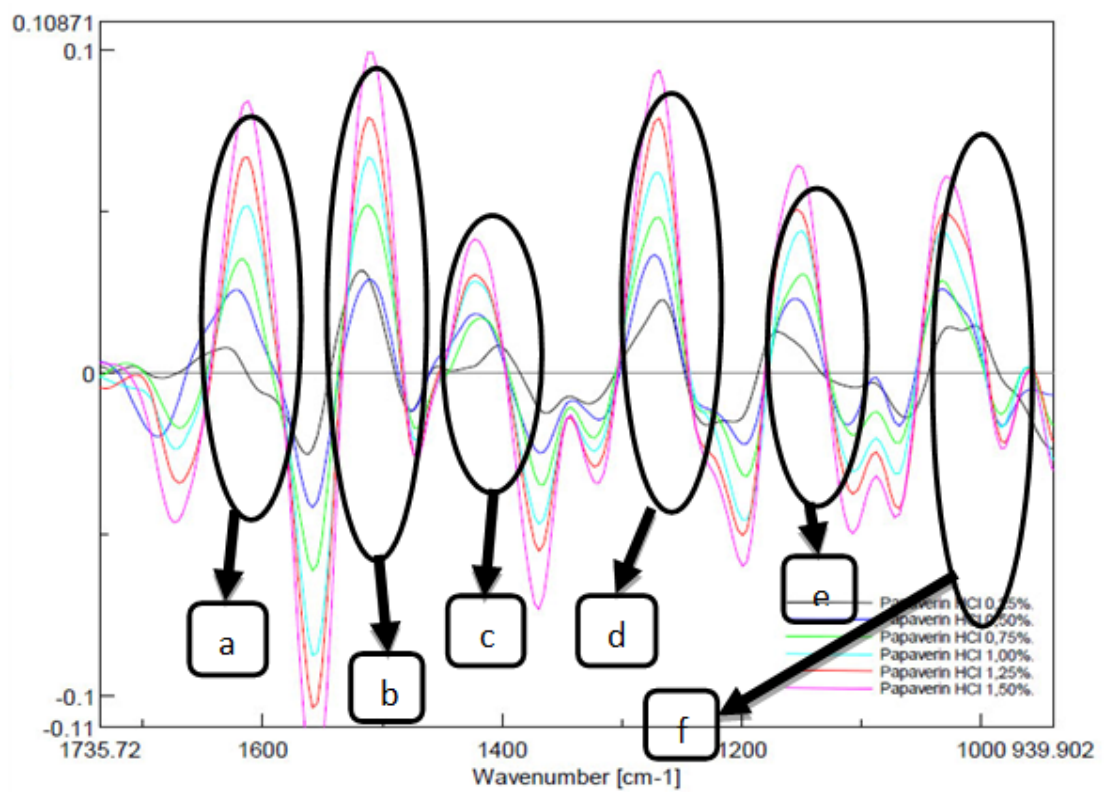

Fig. 3: Derivated absorbance-spectra of papaverin HCl standard at: a) $1670-1575 \mathrm{~cm}^{-1}$, b) $1550-1475 \mathrm{~cm}^{-1}$, c) $1480-1370 \mathrm{~cm}^{-1}$, d) 1320 $1230 \mathrm{~cm}^{-1}$, e) $1200-1110 \mathrm{~cm}^{-1}$, f) $1070-975 \mathrm{~cm}^{-1}$

\section{Spectra selection}

Fig. 3 shows the spectrum of derivatization of raw papaverine $\mathrm{HCl}$ in a varies concentrations in several wavenumbers. Furthermore, the AUC for each derivated absorbance spectra in the range of wave numbers was determined. Then, each was plotted against the concentration of papaverine $\mathrm{HCl}$ to test linearity. Table 1 shows the data collected and the coefficient of correlation ( $\mathrm{r}$ ) for each range of wave numbers. Spectra at $1320-1230 \mathrm{~cm}^{-1}$ had the highest correlation coefficient, with $r=0.9999$. As noted, the calibration curve will be revealed in the subchapter of linearity. Therefore, this area was next used as the quantitative-based of the sample's assay method. 
Table 1: AUC of absorbance-derivate spectra of papaverine $\mathrm{HCl}$ in a vary concentrations

\begin{tabular}{|c|c|c|c|c|c|c|}
\hline \multirow[t]{2}{*}{$\mathrm{C}(\% \mathrm{w} / \mathrm{w})$} & \multicolumn{6}{|c|}{ AUC average $\pm S D$ at the wavelength area $\left(\mathrm{cm}^{-1}\right)^{*}$} \\
\hline & $1670-1575$ & $1550-1475$ & $1480-1370$ & 1320-1230 & 1200-1110 & $1070-975$ \\
\hline 0.25 & $0.2639 \pm 0.0036$ & $1.0160 \pm 0.0467$ & $0.2371 \pm 0.0136$ & $0.7277 \pm 0.0154$ & $0.3995 \pm 0.0146$ & $0.6449 \pm 0.0863$ \\
\hline 0.50 & $1.0672 \pm 0.0627$ & $0.9718 \pm 0.1033$ & $0.6925 \pm 0.0159$ & $1.2182 \pm 0.0173$ & $0.7508 \pm 0.0077$ & $0.9976 \pm 0.0109$ \\
\hline 0.75 & $1.1677 \pm 0.0623$ & $1.8649 \pm 0.0290$ & $0.6358 \pm 0.0961$ & $1.7452 \pm 0.0124$ & $1.0326 \pm 0.0152$ & $1.0540 \pm 0.1335$ \\
\hline 1.00 & $1.8239 \pm 0.0079$ & $2.1602 \pm 0.0400$ & $0.9707 \pm 0.0102$ & $2.2810 \pm 0.0425$ & $1.3988 \pm 0.0224$ & $1.5202 \pm 0.1646$ \\
\hline 1.25 & $2.1619 \pm 0.0794$ & $2.3989 \pm 0.1615$ & $1.0533 \pm 0.0394$ & $2.8059 \pm 0.0415$ & $1.6939 \pm 0.0904$ & $1.9301 \pm 0.0545$ \\
\hline 1.50 & $3.0038 \pm 0.2234$ & $3.2052 \pm 0.0294$ & $1.3813 \pm 0.1180$ & $3.3229 \pm 0.1737$ & $2.1592 \pm 0.1899$ & $2.1666 \pm 0.0804$ \\
\hline Coefficient correlation (r) & 0.9684 & 0.9471 & 0.9312 & 0.9999 & 0.9952 & 0.974 \\
\hline
\end{tabular}

Note: C: concentration of papaverine $\mathrm{HCl}, \mathrm{AUC}$ : area under the curve of absorbance, SD: standard deviation. *All values are reported as mean \pm SD ( $\mathrm{n}=3$ )

\section{Validation of method}

\section{Specificity test}

Specificity test was carried out by comparing FTIR spectra from hair, standard of papaverine $\mathrm{HCl}$, and the mixture of both. Fig. 4 shows that the spectrum produced by papaverine $\mathrm{HCl}$ was almost the same as the mixed spectrum of hair-papaverine $\mathrm{HCl}$. Nevertheless, there was a difference spectra at $3400 \mathrm{~cm}^{-1}$, which indicated the presence of an $\mathrm{OH}$ group produced by the mixture. The peak also belongs to the hair spectrum. At the wave-numbers $1500-1000 \mathrm{~cm}^{-1}$, there was a sharp peak on the spectrum of papaverine $\mathrm{HCl}$, and the spectrum produced by the hair-papaverine mixture. However, at the wave number, there is no peak spectrum of the hair.

This is showing that no interference of hair as the matrix towards papaverine $\mathrm{HCl}$ measurement. Then this spectra can be set as the specific for quantification.

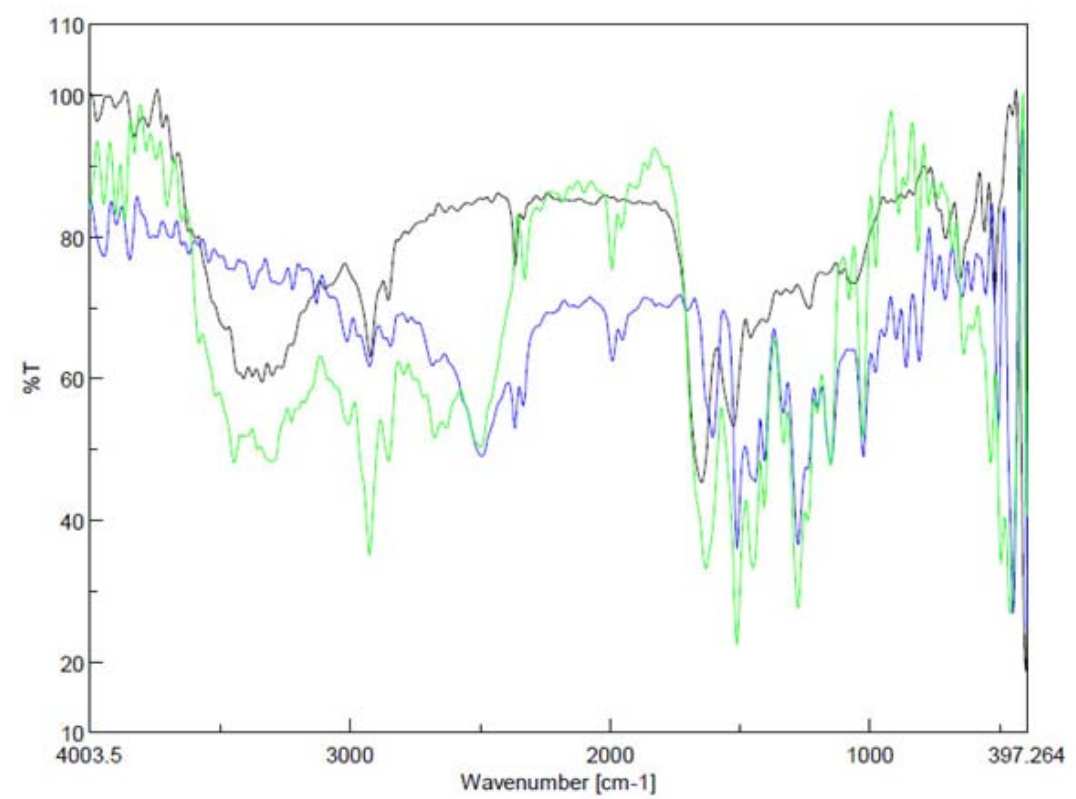

Fig. 4: Spectrum FTIR of: hair (black curve), papaverine HCl (blue curve) and the mixture of both matters (green curve)

\section{Linearity test}

The linearity test was carried out by plotting six concentrations of papaverine $\mathrm{HCl}$ in potassium bromide $(0.25-1.5 \% \mathrm{w} / \mathrm{w})$ against derivative AUC at wave numbers $1320-1230 \mathrm{~cm}^{-1}$. Each concentration was tested three times. Regression equations and correlation coefficients were obtained by plotting the concentration of the drug against AUC. Table 2 shows the AUC produced from the spectrum of raw derivatives of papaverine $\mathrm{HCl}$ for each concentration.

Table 2: Linearity data of papaverine $\mathrm{HCl}$ standard in the hair sample

\begin{tabular}{ll}
\hline $\mathbf{C}(\% \mathbf{~ w} / \mathbf{w})$ & AUC of derivated absorbance spectra $^{*}$ \\
\hline 0.25 & $0.7277 \pm 0.0154$ \\
0.50 & $1.2182 \pm 0.0173$ \\
0.75 & $1.7452 \pm 0.0124$ \\
1.00 & $2.2810 \pm 0.0425$ \\
1.25 & $2.8059 \pm 0.0415$ \\
1.50 & $3.3229 \pm 0.1737$ \\
\hline
\end{tabular}

Note: $\mathrm{C}$ : concentration of papaverine $\mathrm{HCl}, \mathrm{AUC}$ : area under the curve of absorbance, *All values are reported as the mean of average $\pm \mathrm{SD}(\mathrm{n}=3$ ), from the data, a calibration curve was composed with the result is shown in fig. 5 as follows. 


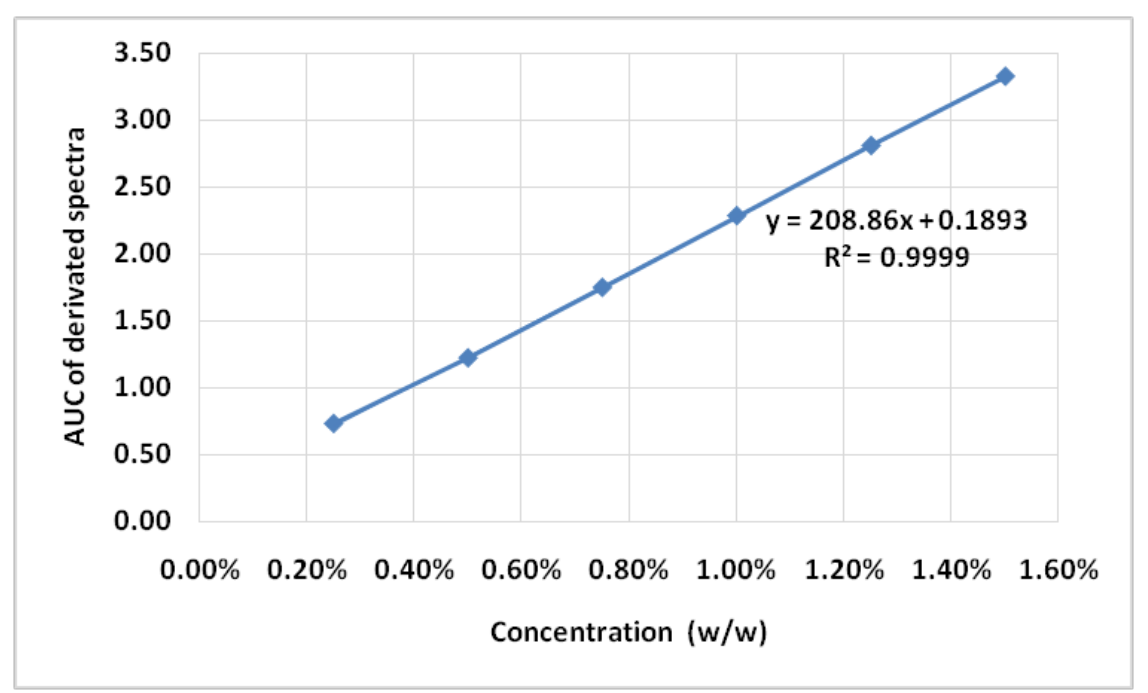

Fig. 5: The calibration curve from the linearity test

Fig. 5 shows that the regression equation obtained for range concentration of $0.25-1.50 \%(w / w)$ was: $y=208.86 x+0.1893$. This result has a correlation coefficient (r) of 0.9999 and Vxo of 0.00206 $\%$. The value of $r$ was obtained $\geq 0.999$ with Vxo $\leq 2.0 \%$, it indicates that the method used has met the acceptance of linearity [24].

\section{Limit of detection and quantification}

Detection and quantification limits were calculated based on data obtained from the linearity test, using the formula as follow:

$$
\begin{gathered}
\mathrm{S}_{\mathrm{y} / \mathrm{x}}=\sqrt{\frac{\sum\left(\mathrm{y}_{1}-\hat{\mathrm{y}}_{1}\right)^{2}}{\mathrm{n}-2}}=0.004303268 \\
\text { Limit of detection (LOD) }=\frac{3 \mathrm{~S}_{\mathrm{y} / \mathrm{x}}}{\mathrm{b}}=0.00618 \% \mathrm{w} / \mathrm{w} \\
\text { Limit of quantification (LOQ) }=\frac{10 \mathrm{~S}_{\mathrm{y} / \mathrm{x}}}{\mathrm{b}}=0.02060 \% \mathrm{w} / \mathrm{w}
\end{gathered}
$$

From the results above, the sensitivity of the instrument for the detection of samples with the smallest concentration was $0.00618 \%$ $\mathrm{w} / \mathrm{w}$. Next a concentration of $0.02060 \% \mathrm{w} / \mathrm{w}$ gave the accurate and precise results.

\section{Range of analysis capacity}

Based on the linearity test, in the concentration range of $0.25-1.50 \%$ $\mathrm{w} / \mathrm{w}$ shows good linearity, accuracy, and precision. So, the concentration range can be used in this method.

\section{Accuracy test}

Accuracy test was carried out by measuring the concentrations of the standard were 80,100 and $120 \%$ and measuring three times for each. Table 3 shows the AUC produced and percent recovery obtained for the concentrations.

Table 3: Accuracy data of papaverin HCl standard

\begin{tabular}{llll}
\hline $\mathbf{C}(\mathbf{\%} \mathbf{w} / \mathbf{w})$ & AUC of derivated spectra & Average of AUC of derivated spectra* & \% recovery \\
\hline 80 & 1.87247 & $1.84331 \pm 0.02527$ & 98.99035 \\
& 1.82961 & & 100.618 \\
100 & 1.82785 & $2.29081 \pm 0.02127$ & \\
& 2.27627 & & 100.355 \\
120 & 2.31522 & $2.70452 \pm 0.01519$ & \\
& 2.28093 & & \\
& 2.69113 & & \\
& 2.72102 & & \\
& 2.70140 & & \\
\end{tabular}

Note: C: concentration of papaverine $\mathrm{HCl}, \mathrm{AUC}$ : area under the curve of absorbance, ${ }^{*}$ All values are reported as mean of average $\pm \mathrm{SD}(\mathrm{n}=3)$

Table 3 reveals the percent of recovery for the concentrations of 80,100 and $120 \% \mathrm{w} / \mathrm{w}$ are in the range of $97-103 \% \mathrm{w} / \mathrm{w}$. It means that the result meets the requirements for acceptance.

\section{Precision test}

The test was carried out by measuring the concentration of $100 \%$ papaverine $\mathrm{HCl}$. It was conducted over three days, with each day was six measurements. Data was taken to obtain intra-day and inter-day precision.

\section{Intra-day precision test}

Table 4 shows the AUC resulted in measuring $100 \%$ papaverine $\mathrm{HCl}$, repeated in three days. From table 4 above, the relative-standarddeviation of intra-day precision obtained from three-day measurement, all were less than $2.0 \%$ so that it meets the requirements for acceptance.

\section{Inter-day precision}

Table 5 shows the average of AUC of derivated-absorbance resulted from measuring $100 \% \mathrm{w} / \mathrm{w}$ papaverine $\mathrm{HCl}$. This test also was carried out on three different days.

From table 5 above, the RSD of the inter-day precision test was less than $2.0 \%$. It means that the result met the acceptance criteria [25]

All validation parameters, namely specificity, linearity, limit of detection, limit of quantification, ranges, accuracy, and precision have been ensured. Furthermore, this method can be used to determine the levels of papaverine $\mathrm{HCl}$ in hair samples, directly without any extraction.

\section{Determination of papaverine $\mathrm{HCl}$ levels in hair samples using FTIR}

The content determination was done on hair that has been soaked in papaverine $\mathrm{HCl}$ solution. Sampling was carried out 
every $24 \mathrm{~h}$. Hairs were cut into very small pieces then dispersed in potassium bromide. The assay was conducted using a validated FTIR method. The results of the analysis are shown in table 6 below.

Table 4: Intra-day precision test result

\begin{tabular}{llcc}
\hline \multirow{2}{*}{ No. } & \multicolumn{3}{l}{ AUC of the derivated spectra on the day-* } \\
\cline { 2 - 4 } & $\mathbf{1}$ & $\mathbf{2}$ & $\mathbf{3}$ \\
\hline 1 & 2.27627 & 2.18784 & 2.23709 \\
2 & 2.31522 & 2.22518 & 2.26770 \\
3 & 2.28093 & 2.22646 & 2.26547 \\
4 & 2.23709 & 2.20305 & 2.24778 \\
5 & 2.32047 & 2.23113 & 2.27357 \\
6 & 2.36127 & 2.25550 & 2.27893 \\
Average of AUC & 2.29854 & 2.22153 & 0.03740 \\
SD & 0.04307 & 0.02350 & 1.64203 \\
RSD (\%) & 1.87392 & 1.05764 & \\
\hline
\end{tabular}

Note: AUC: area under the curve of absorbance, SD: standard deviation, RSD: relative standard of deviation., *All values are reported as one measurement.

Table 5: Inter-day precision data

\begin{tabular}{ll}
\hline The day- & Average of AUC absorbance's derivate* \\
\hline 1 & $2.29854 \pm 0.04307$ \\
2 & $2.22153 \pm 0.02350$ \\
3 & $2.27753 \pm 0.03740$ \\
Average of AUC & 2.29854 \\
SD & 0.03981 \\
RSD (\%) & 1.75695 \\
\hline
\end{tabular}

Note: AUC: area under the curve of absorbance, SD: standard deviation, RSD: a relative of standard deviation, *All values are reported as mean of average \pm standard deviation with $\mathrm{n}=3$.

Table 6: Papaverine HCl content of the hair sample

\begin{tabular}{lll}
\hline The h of- & Average of AUC & Papaverin HCl level $(\% \mathbf{~ w} / \mathbf{w})^{*}$ \\
\hline 72 & $0.238223 \pm 0.000677$ & $0.0234 \pm 0.0003$ \\
96 & $0.243545 \pm 0.003363$ & $0.0260 \pm 0.0016$ \\
120 & $0.305179 \pm 0.003702$ & $0.0555 \pm 0.0018$ \\
144 & $0.387432 \pm 0.002576$ & $0.0949 \pm 0.0012$ \\
168 & $0.444529 \pm 0.001718$ & $0.1222 \pm 0.0017$ \\
192 & $0.522187 \pm 0.002278$ & $0.1594 \pm 0.0011$ \\
\hline
\end{tabular}

Note: AUC: area under the curve of absorbance, ${ }^{*}$ All values are reported as mean of average \pm standard deviation with $\mathrm{n}=3$.

As sample preparation, papaverine $\mathrm{HCl}$ in this analysis simulation was entered into the hair externally. Surely the compound also can be entrapped internally, because hair is continually fed by blood, which contains everything that entered the body [3-7]. For the real and factual condition, hair sample should be taken after one-month usage, in an assumption that hair growing $1 \mathrm{~cm} /$ month [26-29].

As explained before, the method has the limit of detection and quantification as $0.00618 \% \mathrm{w} / \mathrm{w}$ and $0.02060 \% \mathrm{w} / \mathrm{w}$. Data showed, before $72 \mathrm{~h}$ (three days) the drug can't be determined quantitatively, because the response was smaller than the quantification limit. After the time, papaverine $\mathrm{HCl}$ level increasing and was over the limit of quantification. The response clear yet and can be analyzed accurate and precisely. Therefore, the method was applicable to determine papaverine $\mathrm{HCl}$ in hair using FTIR, without any extraction and dilution.

Nothing perfect, on the other hand, this method has disadvantages too. Mainly are the lower of specificity and sensitivity than other instrumentations. Nevertheless, the derivation as a mathematicalmanipulation has been proven can increase the specificity. As comparison, the sensitivities of FTIR methods calculated as approximately are 100-200 times lower than HPLC. However, it is almost equal compared to spectrophotometry uv-visible [9, 30,31]. Fortunately, this method in the next development, still can be improved by the standard addition method. This way is commonly used to increase the response besides the derivation mathematically support [32]. On the future, this should be attempted to support and improve the sensitivity [32]. Furthermore, based on over experience, FTIR's procedure was shown very easy and simple. Moreover, due to the free of organic solvent, this method can be stated as the greener, more economic and efficient. Briefly, it is suitable to be used as a rapid method for papaverine $\mathrm{HCl}$ quantification in the hair sample.

\section{CONCLUSION}

FTIR has been proven to be adequate and suitable for determining the levels of papaverine $\mathrm{HCl}$ in hair samples. The specific spectra lays at $1320-1230 \mathrm{~cm}^{-1}$, with the detection and quantitation limits are 0.00618 and $0.02060 \% \mathrm{w} / \mathrm{w}$ respectively. This method showed advantages on its simplicity and efficiency due to not need any extraction. Therefore, it can be stated as the greener, rapid and costefficient.

\section{ACKNOWLEDGMENT}

This research was funded by the Capacity Improvement Research Program 2018, Research and Community Service Institution, Bandung Institute of Technology, (LPPM ITB), Indonesia.

\section{AUTHORS CONTRIBUTIONS}

All the author have contributed equally 


\section{CONFLICT OF INTERESTS}

Declared none

\section{REFERENCES}

1. World Health Organization. Neuroscience of psychoactive substance use and dependence. Switzerland: WHO Library Cataloguing-in-Publication Data; 2004. p. 9, 12, 13.

2. Kaye P, Agrawal YK, Gupta S, Patel C, Patel I. Determination of trazodone in human plasma by reversed-phase liquid chromatography-mass spectrometry with electrospray ionisation. Int J Pharm Pharm Sci 2014:6:300-4.

3. Laureen J, Marinetti MS. Review of: hair analysis in clinical and forensic toxicology. J Forensic Sci 2017;62:1426-9.

4. Oien CT. Forensic hair comparison: background information for interpretation. FORENSIC Sci Comm 2009;11:2.

5. Pragst F, Balikova MA. State of the art in hair analysis for detection of drug and alcohol abuse. Clin Chim Acta 2006;370:17-49.

6. Kintz P. Hair analysis in forensic toxicology: an updated review with a special focus on pitfalls. Curr Pharm Des 2017;23:5480-6.

7. Welch MJ, Sniegoski LT, Allgood CC, Habram M. Hair analysis for drugs of abuse: evaluation of analytical methods, environmental issues, and development of reference materials. J Anal Toxicol 1993;17:389-98.

8. Rustin Y. Detection of papaverine for the possible identification of illicit opium cultivation. Anal Chem 2017;89:1684-8.

9. Mercolini L, Mandrioli R, Saladini B, Conti M, Baccini C, Raggi MA. Quantitative analysis of cocaine in human hair by HPLC with fluorescence detection Augusta Raggia. J Pharm Biomed Anal 2008;48:456-61.

10. Lachenmeier K, Musshoff F, Madea B. Determination of opiates and cocaine in hair using automated enzyme immunoassay screening methodologies followed by gas chromatographicmass spectrometric (GC-MS) confirmation. Forensic Sci Int 2006;159:189-99.

11. Ellis DI, Royston G. Metabolic fingerprinting in disease diagnosis: biomedical applications of infrared and raman spectroscopy. Roy Soc Chem J 2006;131:876.

12. Nugrahani I, Citra K. Determination of thiamine $\mathrm{HCl}$ (vitamin B1) and pyridoxine $\mathrm{HCl}$ (vitamin B6) content in tablet by FTIR. Int J Pharm Pharm Sci 2016;8:258.

13. United Nations Office on Drugs and Crime. Guidelines for testing drugs under international control in hair, sweat and oral fluid. New York: Laboratory and Scientific Section UNODC; 2014. p. 7-9.

14. National Health and Nutrition Examination Survey. Specimen collection procedures manual. USA: Centers for Disease Control and Prevention; 2000. p. 4-7.

15. Ministry of Health of Republic of Indonesia PharmacopoeiaIndonesia. 5th ed. Jakarta: Ministry of Health of Republic of Indonesia; 2014.
16. Sweetman SC. Martindale: the complete drug reference. 36th ed. London: Pharmaceutical Press; 2009. p. 2191-2.

17. Cresswell CJ. Analisis spektrum senyawa organik. Bandung: Penerbit ITB; 2005. p. 60.

18. Skoog DA, Crouch SR, Holler FJ. Principles of instrumental analysis. 6th ed. Belmont: Thomson Higher Education; 2007. p. 439-41.

19. Pienpinijthama P, Thammacharoena C, Naranitad S, Ekgasita S. Analysis of cosmetic residues on a single human hair by ATR FT-IR microspectroscopy. Spectrochim Acta Part A 2018;197:230-6.

20. Zhang L, Hassan S. Fourier transform infrared (ftir) in diabetes research by analyzing hair samples. J N C Acad Sci 2007;123:163-6.

21. Mujeeb MA, Zafar MKM. FTIR spectroscopic analysis on human hair. Int J Innov Res Sci Eng Technol 2017;6:9327-32.

22. Chan CC. Analytical method validation and instrument performance verification. New Jersey: John Wiley and Sons; 2004. p. 75-9.

23. International Conference of Harmonization, Q2 Validation of analytical procedures: text and methodology international conference on harmonization of technical requirements for registration of pharmaceutical for human use, ICH Harmonized Tripartite Guideline, Canada; 2005. p. 6-13.

24. Sharma S, Goyal S, Chauhan K. A review on analytical method development and validation. Int J Appl Pharm 2018;10:8-15.

25. Riyanto. Validasi and verifikasi metode uji. Yogyakarta: Deepublish Publisher; 2002. p. 23-4, 28, 40-2, 53-4, 65-6.

26. Olufunso OS, Matthew 0 . Spectrophotometric determination of chloroquine in the hair of mice. Asian J Biomed Pharm Sci 2014;4:15-8.

27. Tzatzarakis MN. Comparative evaluation of drug deposition in hair samples collected from different anatomical body sites. J Anal Toxicol 2017;41;214-23.

28. Khajuria H, Nayak BP, Badiye A. Toxicological hair analysis: pre-analytical, analytical and interpretive aspects. Med Sci Law 2018;10:1-10.

29. Balikova M. Hair analysis for drugs of abuse: plausibility of interpretation. Biomed Pap Med Fac Univ Palacky Olomouc Czech Repub 2005;149:199-207.

30. Samanidou V, Pantazidou K, Kovatsi L, Njau S, Livanos A. A simple HPLC method for the simultaneous determination of two selective serotonin reuptake inhibitors and two serotoninnorepinephrine reuptake inhibitors in hair, nail clippings, and cerebrospinal fluid. J Sep Sci 2012;35:839-45.

31. Kasperek R. Determination of diclofenac sodium and papaverine hydrochloride in tablets by HPLC method. Acta Pol Pharm Drug Res 2008;65:403-8.

32. JoVE Science Education Database. Method of standard addition. Anal Chem; 2018 